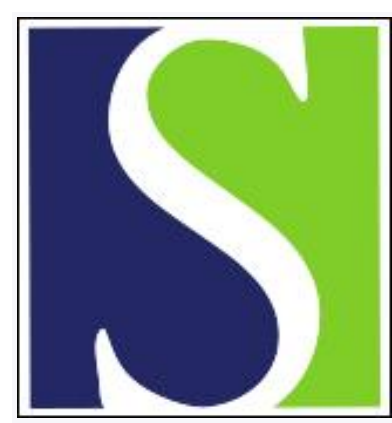

Scand J Work Environ Health 1992;18(4):233-241

https://doi.org/10.5271/sjweh.1584

Issue date: 01 Aug 1992

Empirical assessment of the effect of different summary worklife exposure measures on the estimation of risk in case-referent studies of occupational cancer.

by Suarez-Almazor ME, Soskolne CL, Fung K, Jhangri GS

Affiliation: Department of Health Services Administration and Community Medicine, University of Alberta, Edmonton, Canada.

This article in PubMed: www.ncbi.nlm.nih.gov/pubmed/1411365

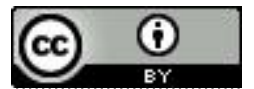




\title{
Empirical assessment of the effect of different summary worklife exposure measures on the estimation of risk in case-referent studies of occupational cancer
}

\author{
by Maria E Suarez-Almazor, MD, ${ }^{1}$ Colin L Soskolne, $\mathrm{PhD},{ }^{1}$ Karen Fung, $\mathrm{PhD},{ }^{2}$ \\ Gian S Jhangri, MSc ${ }^{1}$
}

\begin{abstract}
SUAREZ-ALMAZOR ME, SOSKOLNE CL, FUNG K, JHANGRI GS. Empirical assessment of the effect of different summary worklife exposure measures on the estimation of risk in case-referent studies of occupational cancer. Scand J Work Environ Health 1992;18:233-41. The effect of different summary measures of worklife exposure on the estimation of risk is reported. Two matched case-referent studies associating sulfuric acid exposure and cancer from Baton Rouge and southern Ontario were used. Five summary exposure measures were converted to discrete levels of exposure through the selection of equivalent percentile points on each measure's respective percentage frequency distribution for logistic regression modeling purposes. The southern Ontario data set exhibited only minor differences across all five exposure measures. The Baton Rouge data set, however, produced different results, and the time-dependent measures appeared to underestimate risk. It is possible, therefore, to obtain different estimates of risk depending on the exposure measure selected. It is recommended that, in the absence of proved models for assessing exposure, a variety of summary measures be used to estimate risk. This approach would facilitate the comparison of findings across studies.
\end{abstract}

Key terms: case-control study, job-exposure matrix, laryngeal cancer, occupational histories, odds ratio, respiratory tract cancer, sulfuric acid.

One of the major impediments to etiologically oriented occupational health studies is the paucity of data on individual exposures. Researchers must devise effect measures in the form of indices of exposure to putative hazardous agents. These are usually calculated from estimates of (i) duration of tasks or of assignments at defined employment locations and (ii) concentrations of agents at those sites and times. Even when duration and concentration variables have been well assessed, there remain problems in the choice of the most appropriate summary measure by which to classify each worker's lifetime exposure experience.

A summary exposure measure is determined by the respective weight it attributes to either duration or concentration of exposure or both. Thus different measures may produce different results (1). Ideally, the summary measure selected should be based on a set of defensible assumptions regarding the postulated biological mechanism for the agent or disease association under study (2). This procedure is not, however, always possible. Very often, the biological effect of the duration of exposure or the concentration of the agent under study is unknown. In this context the

\footnotetext{
1 Epidemiology Program, Department of Health Services Administration and Community Medicine, University of Alberta, Edmonton, Alberta, Canada.

2 Department of Mathematics and Statistics, University of Windsor, Windsor, Ontario, Canada.
}

Reprint requests to: Dr Colin L Soskolne, Epidemiology Program, 13-103 Clinical Sciences Building, University of Alberta, Edmonton, Alberta, T6G 2G3 Canada. use of different exposure measures may be useful to suggest a mechanism by which exposure exerts its effect.

We have compared five summary worklife exposure measures in two different matched case-referent studies in which excess upper respiratory cancers were related to the use of sulfuric acid. The first study was conducted among workers in an oil refinery and chemical plant in Baton Rouge, Louisiana $(3,4)$. The second study was population based, conducted among residents of four cities in southern Ontario (5). We estimated the effect of reclassification on the strength of the association between sulfuric acid and upper respiratory cancer by recategorizing the exposure measures according to different percentile points of the frequency distribution of exposure among the subjects.

\section{Materials and methods}

\section{Baton Rouge study}

In 1977, an apparent excess of cases of upper respiratory tract cancer was reported in a major oil refinery and chemical plant in Baton Rouge, Louisiana. Investigations implicated the ethanol manufacturing process which required strong concentrations of sulfuric acid. Speculation was that diethyl sulfate, a by-product of the manufacturing process, was the carcinogen (6). A matched case-referent design was proposed to test an etiologically based hypothesis associating sulfuric acid with the development of upper respiratory tract cancer. 
Between 1909 and 1980, 26906 persons had worked at least $1 \mathrm{~d}$ in the plant. Records on 22776 of those who were no longer employed at the plant as of 1980 are kept in an inactive medical records file. Records on the remaining 4130 were those of the currently active employees.

Cases $(\mathrm{N}=50)$ of upper respiratory tract cancer diagnosed between July 1944 and August 1980 were identified from the company's medical department $(78 \%)$ and from the regional tumor register $\mathbf{2 2 \%}$ ). At least three referents were individually matched to each case by random selection from the 26906 medical records for a total of 175 referents. The cases and referents were matched for age (within three years), gender, race, and year of starting employment (the last to control for period effects, within three years). Minimum employment of 12 continuous months was required for inclusion; exposure was considered through the date of diagnosis in each matched set.

During the early stages of the case-referent study, it became apparent that the frequency distribution of duration of employment was bimodal with a significantly higher peak for employees with shorter term service than for longer term employees. Since the cases tended to come from the longer term workers, matching without reference to duration of employment would have resulted in referents with significantly shorter periods of employment. Hence such referents would have a reduced opportunity for exposure to sulfuric acid in a work setting known for multiple exposure changes over time. Thus, to ensure equal opportunity for exposure between the cases and referents, comparable observation windows were achieved through matching on duration of employment (within four years).

The results of this case-referent study have been previously reported, and they showed a significant association between sulfuric acid exposure and upper respiratory tract cancer $(3,4)$. The final model included the effects of tobacco, alcohol, and ear, nose and throat (ENT) disease. Only 43 out of the 50 cases and their matched referents were included in this final analysis, since seven of the case-referent matched sets had incomplete medical information on ENT history; 30 of the 43 cases $(70 \%)$ were laryngeal cancers.

Exposure assessment. In the absence of personal exposure measurements over time an exposure dictionary analogous to that reported by Gamble \& Spirtas (7) was created by considering all unique job changes for all 225 study subjects, regardless of case or referent status. This procedure resulted in a listing of 3995 unique job entries sorted for plant site (refinery versus chemical plant), location (unit for process workers and department for mechanical workers), occupation (activity assigned, eg, pipe fitter), and era (calendar period of employment in the specific occupation).
A scale was then developed to assign retrospectively a grade for the likely degree of exposure (ie, the relative concentration equivalent) that could be associated with each plant site-location-occupation-era-dictionary entry. The final grade was assigned with the use of an ordinal scale with a range of 0 to 5 .

\section{Southern Ontario study}

Between 1977 and 1979, Burch et al conducted a casereferent study of laryngeal cancer in southern Ontario (5). Asbestos and nickel were the factors specifically examined in the etiology of laryngeal cancer, the effects of tobacco and alcohol being controlled. A recent study at the University of Alberta (8) has examined the association between sulfuric acid exposure and the development of laryngeal cancer using the same data collected by Burch et al.

Cases were defined in this study as anyone, with histologically confirmed carcinoma of the larynx newेly diagnosed between March 1977 and July 1979. The patients were residents of Toronto, Hamilton, Sudbury, or North Bay. Cases were ascertained through the only two cancer treatment centers in the study area, which are the Princess Margaret Hospital in southern Ontario and the Hamilton Cancer Clinic. ENT specialists referred the few remaining cases who did not seek radiotherapy treatment at one of the two cancer centers. Of 258 patients, $204(79 \%)$ were included. The rest either refused or died before the interview could be conducted.

Each case was matched with a neighborhood referent obtained through door-to-door solicitation according to a systematic method. Cases and referents were matched for gender, residence, and age (plus or minus five years). The Burch et al study was conducted using male and female case-referent pairs. For the recent study, only male cases and referents were included, the result being a total of 183 matched pairs. The primary data on all of the cases and referents were collected through home-based interviews by specially trained interviewers (9). In addition to questions on demographic data, smoking and alcohol use, a detailed occupational history was recorded by the interviewer. Since Burch et al were not concerned with testing an acid-related hypothesis, occupational histories computerized to tape for their purposes included details only on asbestos and nickel exposures. However, all work history details were recorded and exist in source documents completed in the interview. Exposure was considered through the date of diagnosis in each matched set.

Exposure assessment. A retrospective exposure assessment was performed by the group of expert chemists and industrial hygienists in Montreal, led by Siemiatycki. The retrospective exposure estimates were assigned for all job entries using job title and occupa- 
tion and industry details as provided in the interview (10-12). Thereafter, exposure was estimated according to three measures, each one using a four point scale $(0-3)$ : (i) concentration of exposure (low, medium, and high); (ii) frequency of exposure during a normal week ( $<5 \%, 5-30 \%$, and $>30 \%$ of work time); (iii) degree of certainty with which concentration and frequency were respectively assigned (possible, probable, and definite). The final formula for exposure grade was given by the square of the product of concentration, frequency and certainty; squaring more accurately reflects the way the Montreal groups assigned categories related to each other in practice (11).

\section{Summary worklife exposure measures}

Five different summary worklife exposure measures were used in the present study (table 1).

Cumulative exposure index. The cumulative exposure index (CEI) is the equivalent of "dose" in toxicologic studies and represents the sum, over a working lifetime, of the products of exposure grade and exposure duration for each successive job title. It includes time in its units.

Mean grade. The mean grade (MG) cumulates the products of exposure grade and exposure duration for each successive job title and change (ie, the CEI) and divides by the total time exposed at any grade greater than zero. MG is independent of time in its units; the summary measure for a person exposed for a long period at a high concentration will be similar to that for a person exposed for a short period at a high concentration. Within any matched set, MG is an average grade of exposure per unit of time exposed. It is an average grade for the time actually exposed to the agent under consideration.

Highest grade ever. The highest grade ever (HG) was determined from scanning the work history for the highest grade assignment in the period of observation to which the worker was exposed for at least $7 \mathrm{~d}$. The HG could misrepresent a person's worklife exposure because, by its very formulation, it is based on a maximizing rather than on an averaging procedure and is therefore independent of duration of exposure in its units.

Time-weighted average grade. The time-weighted average (TWA) grade is the cumulative exposure index (CEI) divided by the total time employed. Within any matched set, the TWA grade averages over total time employed. It differs from MG, which averages only over total time actually exposed. Thus TWA grade can be viewed as an average exposure per unit of time in the full term of employment regardless of exposure per se.

Total time exposed. The total time exposed (TTE) accumulates all time periods associated with exposure in units of time. TTE has appeal for its simplicity. However, it is well accepted that health effects must be related not only to duration of chemical exposure, but also to the intensity of that exposure (ie, the concentration or grade).

\section{Analysis}

Logistic regression using conditional maximum likelihood estimation techniques was used to calculate the odds ratios (13), using EGRET ${ }^{\circledR}$ software for personal computers (14). Four variables were included in the modeling for the Baton Rouge study [ie, exposure and three confounders - ENT history (dichotomy), alcohol consumption (dichotomy), and tobacco consumption (trichotomy)]. In the southern Ontario study three variables were included in the modeling [ie, exposure and two confounders - alcohol and tobacco consumption (four ordinal categories each)]. Several models were examined for each study. The confounding variables were kept constant in all of the models.

Exposure (estimated by all five summary measures) was categorized in several ways for inclusion in each model. The subjects were reclassified into different categories of exposure through the selection of percentile points on each measure's respective percentage frequency distribution.

\section{Results}

\section{Baton Rouge study}

Part 1 . The original study had reported exposure based on the mean grade (MG). This variable had been categorized according to the frequency distribution of all 50 matched sets as no or low (approximately lowest $20 \%$ ), moderate (approximately middle $60 \%$ ), and high (approximately highest $20 \%$ ). In the frequency

Table 1. Formulas and dimensions or units of the five selected summary measures of worklife exposure.

\begin{tabular}{|c|c|c|}
\hline Exposure measure & Formula & $\begin{array}{l}\text { Dimensions/ } \\
\text { units }\end{array}$ \\
\hline $\begin{array}{l}\text { Cumulative exposure } \\
\text { index (CEI) }\end{array}$ & $\Sigma$ (grade $x$ time exposed) & Grade and time \\
\hline Mean grade (MG) & $\frac{\Sigma \text { (grade } \times \text { time exposed) }}{\text { Total time exposed }}$ & Grade \\
\hline $\begin{array}{l}\text { Highest grade ever } \\
(H G)\end{array}$ & $\begin{array}{l}\text { Highest grade to which } \\
\text { exposed for } 7 \mathrm{~d}\end{array}$ & Grade \\
\hline $\begin{array}{l}\text { Time-weighted-average } \\
\text { (TWA) grade }\end{array}$ & $\frac{\Sigma(\text { grade } \times \text { time exposed })}{\text { Total time employed }}$ & Grade \\
\hline $\begin{array}{l}\text { Total time exposed } \\
\text { (TTE) }\end{array}$ & Time exposed & Time \\
\hline
\end{tabular}


distribution of the 43 matched sets finally included (with available information and ENT history), the cutoffs corresponded to the $\mathbf{1 8 . 6}$ and 78.4 percentile points. All five summary exposure measures were then trichotomized according to these percentile points. The results are shown in table 2. CEI, MG, TWA grade, and TTE were categorized according to identical percentile points and thus contained the same numbers of subjects in each exposure group. The highest grade (HG), being the only discrete measure with only six values $(0-5)$, could not be categorized according to the same distribution. Thus the closest percentile points were chosen. The odds ratios of the association between exposure to sulfuric acid and upper respiratory tract cancer varied for each summary measure used, from 0.58 to 4.69 for those moderately exposed and from 0.70 to 5.20 for those highly exposed. Only MG (high) and HG (moderate) achieved statistical significance.

Part 2. In this model exposure was categorized through the selection of a percentile point that could be identical for all summary exposure measures (table 3 ). Thus exposure was dichotomized as no or low (lower 15.5\%) and as moderate or high (upper $84.5 \%$ ). The distribution of subjects according to their degrees of exposure was equal for all of the measures, but it varied when disease status (ie, case or referent) was considered. The odds ratios varied from 0.65 to 4.45 .
Part 3. To examine the effect of reclassification, we examined several models by using MG (table 4). MG was a continuous variable with a range in this sample from 0 to 4.20. The no-or-low group was kept constant in all four models and comprised the lower $18.6 \%$ of the MG frequency distribution, which translated into an MG range of $0-1.09$. The moderate- and highexposure groups were reclassified according to different values of MG.

The fourth model was identical to that reported in the original publication (4). In the first three models the moderate- and high-exposure groupings were reclassified by changing the MG cutoff by adding a second decimal point $(1.99,2.00,2.01)$. The odds ratios varied from 3.98 to 5.41 (high versus no or low) and 1.83 to 3.30 (moderate versus no or low). Thirty-five subjects from the high-exposure category were regrouped into the moderate category when the cutoff point was increased from 1.99 to 2.00 .

\section{Southern Ontario study}

Part 1. In this model, exposure to sulfuric acid was trichotomized as no exposure (exposure $=0$, comprising $37.4 \%$ of the sample), low exposure (lower $48.5 \%$ of those exposed, including $30.3 \%$ of the total sample), high exposure (upper $51.5 \%$ of those exposed, including $32.3 \%$ of the total sample). The cutoff was chosen at the 48.5 percentile, as all frequency distributions of the five different summary measures could be

Table 2. Odds ratios and $95 \%$ confidence intervals obtained in part 1 of the Baton Rouge study. (CEI = cumulative exposure index, $M G=$ mean grade, $H G$ = highest grade ever, $T W A=$ time-weighted average, TTE = total time exposed)

\begin{tabular}{|c|c|c|c|c|c|c|}
\hline \multirow{3}{*}{ Exposure measure } & \multicolumn{4}{|c|}{ Study group } & \multirow{3}{*}{$\begin{array}{l}\text { Odds } \\
\text { ratio }\end{array}$} & \multirow{3}{*}{$\begin{array}{c}95 \% \\
\text { confidence } \\
\text { interval }\end{array}$} \\
\hline & \multirow{2}{*}{$\begin{array}{c}\text { Cases } \\
(\mathrm{N}=43) \\
(\mathrm{N})\end{array}$} & \multirow{2}{*}{$\begin{array}{c}\text { Referents } \\
\left(\begin{array}{c}N=151) \\
(N)\end{array}\right.\end{array}$} & \multicolumn{2}{|c|}{$\begin{array}{c}\text { Total } \\
(N=194)\end{array}$} & & \\
\hline & & & $\mathbf{N}$ & $\%$ & & \\
\hline \multicolumn{7}{|l|}{ CEI } \\
\hline $\begin{array}{l}\text { No or low } \\
\text { Moderate } \\
\text { High }\end{array}$ & $\begin{array}{l}11 \\
22 \\
10\end{array}$ & $\begin{array}{l}25 \\
94 \\
32\end{array}$ & $\begin{array}{r}36 \\
116 \\
42\end{array}$ & $\begin{array}{l}18.6 \\
59.8 \\
21.6\end{array}$ & $\begin{array}{l}0.58 \\
0.70\end{array}$ & $\begin{array}{l}0.22-1.50 \\
0.22-2.18\end{array}$ \\
\hline \multicolumn{7}{|l|}{ MG } \\
\hline $\begin{array}{l}\text { No or low } \\
\text { Moderate } \\
\text { High }\end{array}$ & $\begin{array}{r}4 \\
24 \\
15\end{array}$ & $\begin{array}{l}32 \\
92 \\
27\end{array}$ & $\begin{array}{r}36 \\
116 \\
42\end{array}$ & $\begin{array}{l}18.6 \\
59.8 \\
21.6\end{array}$ & $\begin{array}{c}2.89 \\
5.20^{\mathrm{b}}\end{array}$ & $\begin{array}{c}0.74-11.27 \\
1.23-22.09\end{array}$ \\
\hline \multicolumn{7}{|l|}{$H G$} \\
\hline $\begin{array}{l}\text { No or low } \\
\text { Moderate } \\
\text { High }\end{array}$ & $\begin{array}{r}3 \\
37 \\
3\end{array}$ & $\begin{array}{r}27 \\
113 \\
11\end{array}$ & $\begin{array}{r}30 \\
150 \\
14\end{array}$ & $\begin{array}{r}15.5 \\
77.3 \\
7.2\end{array}$ & $\begin{array}{l}4.6 \mathrm{gb}^{\mathrm{b}} \\
2.40\end{array}$ & $\begin{array}{c}1.03-21.33 \\
0.29-20.15\end{array}$ \\
\hline \multicolumn{7}{|l|}{ TWA grade } \\
\hline $\begin{array}{l}\text { No or low } \\
\text { Moderate } \\
\text { High }\end{array}$ & $\begin{array}{r}10 \\
24 \\
9\end{array}$ & $\begin{array}{l}26 \\
92 \\
33\end{array}$ & $\begin{array}{r}36 \\
116 \\
42\end{array}$ & $\begin{array}{l}18.6 \\
59.8 \\
21.6\end{array}$ & $\begin{array}{l}. \\
0.67 \\
0.59\end{array}$ & $\begin{array}{c}0.27-1.67 \\
0.19-1.80\end{array}$ \\
\hline \multicolumn{7}{|l|}{ TTE } \\
\hline $\begin{array}{l}\text { No or low } \\
\text { Moderate } \\
\text { High }\end{array}$ & $\begin{array}{r}9 \\
27 \\
7\end{array}$ & $\begin{array}{l}27 \\
89 \\
35\end{array}$ & $\begin{array}{r}36 \\
116 \\
42\end{array}$ & $\begin{array}{l}18.6 \\
59.8 \\
21.6\end{array}$ & $\begin{array}{c}. \\
1.15 \\
0.55\end{array}$ & $\begin{array}{c}0.43-3.10 \\
0.17-1.74\end{array}$ \\
\hline
\end{tabular}

a Compared with the lowest exposure category.

b Statistically significant at the $5 \%$ level. 
divided at this exact point and equal total numbers of subjects were included in the exposure groups for each measure. The odds ratios for low exposure varied from 1.94 to 2.43 (table 5). Those for high exposure varied from 3.60 to 4.61 and were all statistically significant. The distribution of laryngeal cancer cases and referents with no exposure to sulfuric acid was as expected, identical for each measure, and no exposure was defined in the same way (equal to 0 ) for each measure. In the Baton Rouge study no exposure was included in the no-or-low exposure group, and it was defined with percentile cutoffs. Reclassification was observed for those who had low exposure, the observed differences among the exposure measures being allowed for.
Part 2. In the original Baton Rouge report, no-or-low exposure was defined as the lower $20 \%$ of the entire sample under study. This figure was adequate since the sample came from an industrial population and only approximately $6 \%$ of the subjects had no previous exposure. The southern Ontario study was populationbased, and thus a greater proportion of individuals was unexposed $(37.4 \%)$. In part 1 , the regrouping of patients occurred only for the low and high group because the unexposed subjects were equal for each exposure measure. To examine the potential effect of reclassification, we regrouped CEI, MG, TWA grade, and TTE as no-or-low exposure (lower 50.5\%), moderate exposure (middle $36.6 \%$ ), and high exposure (up-

Table 3. Odds ratios and $95 \%$ confidence intervals obtained in part 2 of the Baton Rouge study. (CEI = cumulative exposure index, $M G=$ mean grade,$H G=$ highest grade ever, $T W A=$ time-weighted average, $T T E=$ total time exposed)

\begin{tabular}{|c|c|c|c|c|c|c|}
\hline \multirow{3}{*}{ Exposure measure } & \multicolumn{4}{|c|}{ Study group } & \multirow{3}{*}{$\begin{array}{l}\text { Odds } \\
\text { ratio }\end{array}$} & \multirow{3}{*}{$\begin{array}{c}95 \% \\
\text { confidence } \\
\text { interval }\end{array}$} \\
\hline & \multirow{2}{*}{$\begin{array}{c}\text { Cases } \\
(\mathrm{N}=43) \\
(\mathrm{N})\end{array}$} & \multirow{2}{*}{$\begin{array}{c}\text { Referents } \\
(\mathrm{N}=151) \\
(\mathrm{N})\end{array}$} & \multicolumn{2}{|c|}{$\begin{array}{c}\text { Total } \\
(\mathrm{N}=194)\end{array}$} & & \\
\hline & & & $\mathbf{N}$ & $\%$ & & \\
\hline \multicolumn{7}{|l|}{ CEI } \\
\hline $\begin{array}{l}\text { No or low } \\
\text { Moderate or high }\end{array}$ & $\begin{array}{r}8 \\
35\end{array}$ & $\begin{array}{r}22 \\
129\end{array}$ & $\begin{array}{r}30 \\
164\end{array}$ & $\begin{array}{l}15.5 \\
84.5\end{array}$ & 0.75 & $0.29-1.94$ \\
\hline \multicolumn{7}{|l|}{ MG } \\
\hline $\begin{array}{l}\text { No or low } \\
\text { Moderate or high }\end{array}$ & $\begin{array}{r}3 \\
40\end{array}$ & $\begin{array}{r}27 \\
124\end{array}$ & $\begin{array}{r}30 \\
164\end{array}$ & $\begin{array}{l}15.5 \\
84.5\end{array}$ & 4.45 & $0.99-20.08$ \\
\hline \multicolumn{7}{|l|}{ HG } \\
\hline $\begin{array}{l}\text { No or low } \\
\text { Moderate or high }\end{array}$ & $\begin{array}{r}3 \\
40\end{array}$ & $\begin{array}{r}27 \\
124\end{array}$ & $\begin{array}{r}30 \\
164\end{array}$ & $\begin{array}{l}15.5 \\
84.5\end{array}$ & $4.55^{b}$ & $1.01-20.42$ \\
\hline \multicolumn{7}{|l|}{ TWA grade } \\
\hline $\begin{array}{l}\text { No or low } \\
\text { Moderate or high }\end{array}$ & $\begin{array}{r}6 \\
37\end{array}$ & $\begin{array}{r}24 \\
127\end{array}$ & $\begin{array}{r}30 \\
164\end{array}$ & $\begin{array}{l}15.5 \\
84.5\end{array}$ & 1.08 & $0.39-2.97$ \\
\hline \multicolumn{7}{|l|}{ TTE } \\
\hline $\begin{array}{l}\text { No or low } \\
\text { Moderate or high }\end{array}$ & $\begin{array}{r}9 \\
34 \\
\end{array}$ & $\begin{array}{r}21 \\
130 \\
\end{array}$ & $\begin{array}{r}30 \\
164\end{array}$ & $\begin{array}{l}15.5 \\
84.5\end{array}$ & $\dot{0.65}$ & $0.25-1.68$ \\
\hline
\end{tabular}

a Compared with the lowest exposure category.

Statistically significant at the $5 \%$ level.

Table 4. Odds ratios and $95 \%$ confidence intervals obtained in part 3 of the Baton Rouge study. (MG = mean grade)

\begin{tabular}{|c|c|c|c|c|c|c|c|}
\hline \multirow{3}{*}{\multicolumn{2}{|c|}{ Exposure measure (MG) }} & \multicolumn{4}{|c|}{ Study group } & \multirow{3}{*}{$\begin{array}{l}\text { Odds } \\
\text { ratio }\end{array}$} & \multirow{3}{*}{$\begin{array}{c}95 \% \\
\text { confidence } \\
\text { interval }\end{array}$} \\
\hline & & \multirow{2}{*}{$\begin{array}{c}\text { Cases } \\
(\mathrm{N}=43) \\
(\mathrm{N})\end{array}$} & \multirow{2}{*}{$\begin{array}{c}\text { Referents } \\
(\mathrm{N}=151) \\
(\mathrm{N})\end{array}$} & \multicolumn{2}{|c|}{$\begin{array}{c}\text { Total } \\
(\mathrm{N}=194)\end{array}$} & & \\
\hline & & & & $\mathrm{N}$ & $\%$ & & \\
\hline 1) & $\begin{array}{l}\text { No or low }(0-1.09) \\
\text { Moderate }(1.10-1.99) \\
\text { High }(>1.99)\end{array}$ & $\begin{array}{r}4 \\
9 \\
30\end{array}$ & $\begin{array}{l}32 \\
56 \\
63\end{array}$ & $\begin{array}{l}36 \\
65 \\
93\end{array}$ & $\begin{array}{l}18.6 \\
33.5 \\
47.9\end{array}$ & $\begin{array}{l}1.83 \\
5.41^{\mathrm{b}}\end{array}$ & $\begin{array}{l}0.40-8.47 \\
1.27-23.00\end{array}$ \\
\hline 2) & $\begin{array}{l}\text { No or low }(0-1.09) \\
\text { Moderate }(1.10-2.00) \\
\text { High }(>2.00)\end{array}$ & $\begin{array}{r}4 \\
22 \\
17\end{array}$ & $\begin{array}{l}32 \\
78 \\
41\end{array}$ & $\begin{array}{r}36 \\
100 \\
58\end{array}$ & $\begin{array}{l}18.6 \\
51.5 \\
29.9\end{array}$ & $\begin{array}{l}\cdot \\
3.30 \\
3.98\end{array}$ & $\begin{array}{l}\cdot \\
0.84-13.00 \\
0.95-16.70\end{array}$ \\
\hline 3) & $\begin{array}{l}\text { No or low }(0-1.09) \\
\text { Moderate }(1.10-2.01) \\
\text { High }(>2.01)\end{array}$ & $\begin{array}{r}4 \\
22 \\
17\end{array}$ & $\begin{array}{l}32 \\
80 \\
39\end{array}$ & $\begin{array}{r}36 \\
102 \\
56\end{array}$ & $\begin{array}{l}18.6 \\
52.6 \\
28.8\end{array}$ & $\begin{array}{l}3.16 \\
4.26^{\mathrm{b}}\end{array}$ & $\begin{array}{l}0.80-12.49 \\
1.02-17.83\end{array}$ \\
\hline 4) & $\begin{array}{l}\text { No or low }(0-1.09) \\
\text { Moderate }(1.10-2.07) \\
\text { High }(>2.07)\end{array}$ & $\begin{array}{r}4 \\
24 \\
15\end{array}$ & $\begin{array}{l}32 \\
92 \\
27\end{array}$ & $\begin{array}{r}36 \\
116 \\
42\end{array}$ & $\begin{array}{l}18.6 \\
59.8 \\
21.6\end{array}$ & $\begin{array}{l}2.89 \\
5.21^{\mathrm{b}}\end{array}$ & $\begin{array}{l}0.74-11.27 \\
1.23-22.09\end{array}$ \\
\hline
\end{tabular}

a Compared with the lowest exposure category.

b Statistically significant at the $5 \%$ level. 
Table 5. Odds ratios and $95 \%$ confidence intervals obtained in part 1 of the southern Ontario study. (CEI = cumulative exposure index, $M G=$ mean grade, $H G=$ highest grade ever, TWA = time-weighted average, TTE = total time exposed)

\begin{tabular}{|c|c|c|c|c|c|c|}
\hline \multirow{3}{*}{ Exposure measure } & \multicolumn{4}{|c|}{ Study group } & \multirow{3}{*}{$\begin{array}{l}\text { Odds } \\
\text { ratio }^{a}\end{array}$} & \multirow{3}{*}{$\begin{array}{c}95 \% \\
\text { confidence } \\
\text { interval }\end{array}$} \\
\hline & \multirow{2}{*}{$\begin{array}{c}\text { Cases } \\
(N=183) \\
(N)\end{array}$} & \multirow{2}{*}{$\begin{array}{l}\text { Referents } \\
\begin{array}{c}(\mathrm{N}=183) \\
(\mathrm{N})\end{array}\end{array}$} & \multicolumn{2}{|c|}{$\begin{array}{c}\text { Total } \\
(\mathrm{N}=366)\end{array}$} & & \\
\hline & & & $N$ & $\%$ & & \\
\hline \multicolumn{7}{|l|}{ CEI } \\
\hline $\begin{array}{l}\text { No } \\
\text { Low } \\
\text { High }\end{array}$ & $\begin{array}{l}49 \\
56 \\
78\end{array}$ & $\begin{array}{l}88 \\
55 \\
40\end{array}$ & $\begin{array}{l}137 \\
111 \\
118\end{array}$ & $\begin{array}{l}37.4 \\
30.3 \\
32.3\end{array}$ & $\begin{array}{l}1.99 \\
4.61^{b}\end{array}$ & $\begin{array}{c}0.99-4.00 \\
2.23-9.51\end{array}$ \\
\hline \multicolumn{7}{|l|}{ MG } \\
\hline $\begin{array}{l}\text { No } \\
\text { Low } \\
\text { High }\end{array}$ & $\begin{array}{l}49 \\
57 \\
77\end{array}$ & $\begin{array}{l}88 \\
54 \\
41\end{array}$ & $\begin{array}{l}137 \\
111 \\
118\end{array}$ & $\begin{array}{l}37.4 \\
30.3 \\
32.3\end{array}$ & $\begin{array}{c}1.94 \\
4.41^{\mathrm{b}}\end{array}$ & $\begin{array}{l}0.96-3.92 \\
2.19-8.88\end{array}$ \\
\hline \multicolumn{7}{|l|}{ HG } \\
\hline $\begin{array}{l}\text { No } \\
\text { Low } \\
\text { High }\end{array}$ & $\begin{array}{l}49 \\
60 \\
74\end{array}$ & $\begin{array}{l}88 \\
51 \\
44\end{array}$ & $\begin{array}{l}137 \\
111 \\
118\end{array}$ & $\begin{array}{l}37.4 \\
30.3 \\
32.3\end{array}$ & $\begin{array}{l}2.43^{b} \\
3.60^{b}\end{array}$ & $\begin{array}{c}1.21-4.89 \\
1.84-7.03\end{array}$ \\
\hline \multicolumn{7}{|l|}{ TWA grade } \\
\hline $\begin{array}{l}\text { No } \\
\text { Low } \\
\text { High }\end{array}$ & $\begin{array}{l}49 \\
55 \\
79\end{array}$ & $\begin{array}{l}88 \\
56 \\
39\end{array}$ & $\begin{array}{l}137 \\
111 \\
118\end{array}$ & $\begin{array}{l}37.4 \\
30.3 \\
32.3\end{array}$ & $\begin{array}{l}2.01^{b} \\
4.49^{b}\end{array}$ & $\begin{array}{l}1.00-4.02 \\
2.20-9.19\end{array}$ \\
\hline \multicolumn{7}{|l|}{ TTE } \\
\hline $\begin{array}{l}\text { No } \\
\text { Low } \\
\text { High }\end{array}$ & $\begin{array}{l}49 \\
60 \\
74\end{array}$ & $\begin{array}{l}88 \\
51 \\
44\end{array}$ & $\begin{array}{l}137 \\
111 \\
118\end{array}$ & $\begin{array}{l}37.4 \\
30.3 \\
32.3\end{array}$ & $\begin{array}{c}2.40^{b} \\
3.78^{b}\end{array}$ & $\begin{array}{c}\cdot \\
1.19-4.86 \\
1.86-7.67\end{array}$ \\
\hline
\end{tabular}

a Compared with the lowest exposure category.

b Statistically significant at the $5 \%$ level.

Table 6. Odds ratios and $95 \%$ confidence intervals obtained in part 2 of the southern Ontario study. (CEI = cumulative exposure index, $\mathrm{MG}=$ mean grade, $\mathrm{HG}=$ highest grade ever, TWA = time-weighted average, TTE = total time exposed)

\begin{tabular}{|c|c|c|c|c|c|c|}
\hline \multirow{3}{*}{ Exposure measure } & \multicolumn{4}{|c|}{ Study group } & \multirow{3}{*}{$\begin{array}{l}\text { Odds } \\
\text { ratio }\end{array}$} & \multirow{3}{*}{$\begin{array}{c}95 \% \\
\text { confidence } \\
\text { interval }\end{array}$} \\
\hline & \multirow{2}{*}{$\begin{array}{c}\text { Cases } \\
(N=183) \\
(N)\end{array}$} & \multirow{2}{*}{$\begin{array}{c}\text { Referents } \\
(N=183) \\
(N)\end{array}$} & \multicolumn{2}{|c|}{$\begin{array}{c}\text { Total } \\
(\mathrm{N}=366)\end{array}$} & & \\
\hline & & & $\mathrm{N}$ & $\%$ & & \\
\hline \multicolumn{7}{|l|}{ CEI } \\
\hline $\begin{array}{l}\text { No or low } \\
\text { Moderate } \\
\text { High }\end{array}$ & $\begin{array}{l}70 \\
83 \\
30\end{array}$ & $\begin{array}{r}115 \\
51 \\
17\end{array}$ & $\begin{array}{r}185 \\
134 \\
47\end{array}$ & $\begin{array}{l}50.5 \\
36.6 \\
12.8\end{array}$ & $\begin{array}{c}2.79^{b} \\
5.44^{b}\end{array}$ & $\begin{array}{c}1.52-5.13 \\
2.09-14.11\end{array}$ \\
\hline \multicolumn{7}{|l|}{ MG } \\
\hline $\begin{array}{l}\text { No or low } \\
\text { Moderate } \\
\text { High }\end{array}$ & $\begin{array}{l}69 \\
86 \\
28\end{array}$ & $\begin{array}{r}116 \\
48 \\
19\end{array}$ & $\begin{array}{r}185 \\
134 \\
47\end{array}$ & $\begin{array}{l}50.5 \\
36.6 \\
12.8\end{array}$ & $\begin{array}{l}2.62^{\mathrm{b}} \\
3.06^{\mathrm{b}}\end{array}$ & $\begin{array}{c}\cdot \\
1.47-4.68 \\
1.28-7.34\end{array}$ \\
\hline \multicolumn{7}{|l|}{$H G$} \\
\hline $\begin{array}{l}\text { No or low } \\
\text { Moderate } \\
\text { High }\end{array}$ & $\begin{array}{l}64 \\
86 \\
33\end{array}$ & $\begin{array}{r}112 \\
54 \\
17\end{array}$ & $\begin{array}{r}176 \\
140 \\
50\end{array}$ & $\begin{array}{l}48.1 \\
38.3 \\
13.7\end{array}$ & $\begin{array}{l}2.50^{\mathrm{b}} \\
4.72^{\mathrm{b}}\end{array}$ & $\begin{array}{c}1.39-4.47 \\
1.85-12.03\end{array}$ \\
\hline \multicolumn{7}{|l|}{ TWA grade } \\
\hline $\begin{array}{l}\text { No or low } \\
\text { Moderate } \\
\text { High }\end{array}$ & $\begin{array}{l}70 \\
82 \\
31\end{array}$ & $\begin{array}{r}115 \\
52 \\
16\end{array}$ & $\begin{array}{r}185 \\
134 \\
47\end{array}$ & $\begin{array}{l}50.5 \\
36.6 \\
12.8\end{array}$ & $\begin{array}{l}2.94^{\mathrm{b}} \\
5.96^{\mathrm{b}}\end{array}$ & $\begin{array}{c}. \\
1.57-5.52 \\
2.26-15.70\end{array}$ \\
\hline \multicolumn{7}{|l|}{ TTE } \\
\hline $\begin{array}{l}\text { No or low } \\
\text { Moderate } \\
\text { High }\end{array}$ & $\begin{array}{l}70 \\
82 \\
31\end{array}$ & $\begin{array}{r}115 \\
52 \\
16\end{array}$ & $\begin{array}{r}185 \\
134 \\
47\end{array}$ & $\begin{array}{l}50.5 \\
36.6 \\
12.8\end{array}$ & $\begin{array}{c}2.72^{b} \\
5.56^{b}\end{array}$ & $\begin{array}{c}\cdot \\
1.50-4.93 \\
2.16-14.32\end{array}$ \\
\hline
\end{tabular}

a Compared with the lowest exposure category.

b Statistically significant at the $5 \%$ level.

per $12.8 \%$ ). HG could not be categorized at these same percentile points and was regrouped as no-or-low exposure (lower $48.1 \%$ ), moderate exposure (middle
$38.3 \%$ ), and high exposure (upper 13.7\%). For MG, TWA grade, and TTE, the total number of subjects was identical in each of the three exposure groups 
(table 6). Yet there was some reclassification in the distribution of cases and referents among the different exposure measures, and this reclassification accounted for the observed variations in odds ratios, which ranged from 2.50 to 2.94 for moderate exposure and from 3.06 to 5.96 for high exposure.

\section{Discussion}

The objective of this study was to assess empirically variation in risk estimates according to the choice of summary worklife exposure measures.

Several recent reports have documented evidence for deleterious health effects after sublethal acid exposure (3-4, 15-19). For the present analysis we chose two previous case-referent studies reporting an association between laryngeal cancer and worklife exposure to higher levels of sulfuric acid (3-5).

There were some fundamental design differences between both studies that could explain, at least in part, some of the obtained results:

- Study population - the Baton Rouge report was conducted in a refinery and chemical plant, and the cases and referents had all been workers at the plant. The southern Ontario study was population based.

- Selection of cases - the Baton Rouge study included all cases of primary upper respiratory cancer, with the following distribution according to organ sites: $68 \%$ laryngeal, $12 \%$ oropharyngeal, $10 \%$ nose, nasal cavities, middle ear and sinuses, $4 \%$ nasopharyngeal, $4 \%$ hypopharyngeal, and $1 \%$ pharyngeal (unspecified). All of the southern Ontario study cases had a diagnosis of laryngeal cancer.

- Sample size - the Baton Rouge sample comprised 194 individuals (43 cases and 151 referents) for a total of 43 matched sets having complete data. The southern Ontario study included 366 subjects for a total of 183 matched pairs.

- Matching variables - in the Baton Rouge study the cases and referents were matched for age, gender, race, year of first employment, and duration of employment. In the southern Ontario study, the matching variables were gender, age, and residence.

- Estimation of exposure - exposure grade was estimated in the Baton Rouge study by the use of an ordinal scale from 0 to 5 . In the southern Ontario study, the exposure estimation was more detailed, being based on the squared product of three different ordinal variables, each one with a four-point scale (0 to 3 ), rendering a larger number of possible values. - Degree of exposure - in the Baton Rouge study, the case : referent ratio was 1:3-4; however, most of the subjects had some degree of exposure, as they were workers at the same industrial plant (only approximately $6 \%$ had no exposure at all). In the southern Ontario study, $37.4 \%$ of the total sample had never been exposed even though $50 \%$ of the subjects were cases. Differences in the method used for estimating exposure may have also affected the differences observed in the proportions of exposed and unexposed individuals.

Confounding variables - alcohol, tobacco, and previous ENT history were included in the Baton Rouge study, whereas only alcohol and tobacco were included in the southern Ontario study.

The Baton Rouge study showed marked differences in the odds ratios obtained by using different summary exposure measures. We have presented here (tables 2 and 3) two different models using all measures. The categorization of exposure was chosen so that the distribution of subjects according to degree of exposure could be as close as possible for all five measures (ie, cutoff values would correspond to the same percentile point). In the first model (table 2) the distribution of the total number of subjects according to degree of exposure was identical for CEI, MG, TWA grade, and TTE. In the second model, it was equal for all five summary measures. However, the distribution according to disease status varied largely in both models; hence the odds ratios varied below 1 (ie, from a "protective effect") to 5 (ie, a "deleterious effect"). MG and $\mathrm{HG}$ were the only exposure measures that gave a positive risk, and both were statistically significant. This result can be explained by the fact that, in this study, both the cases and referents were matched for duration of employment and both measures were independent of time.

The design of the Baton Rouge study included matching for variables related to time exposed. One cannot then analyze for those variables which are strongly related to the matching variables that either incorporate time measures in their units (ie, CEI and TTE) or include in their formulation a term that is in itself a matching variable (ie, the denominator in TWA grade). The two time-dependent measures, CEI and TTE, demonstrated protective effects as did TWA grade (none statistically significant). It is noteworthy that TWA grade, which is also independent of time, showed as different a risk as that observed with MG ( 0.59 versus 5.20 for high exposure) (table 2). As noted earlier, the cases and referents were matched for duration of employment. It would appear therefore that the influence of the matching was greater for TWA grade (which was weighted by duration of employment) than for MG (weighted by duration of exposure). Thus, as expected, the similarity (by matching) of the cases and referents would be increased for duration of employment as compared with duration of exposure, and thus the effects of exposure would be attenuated.

In part 3 of the Baton Rouge study (table 4), we examined the effect of recategorizing the exposure on the estimation of risk. We used MG as the exposure measure, which had a continuous range from 0 to 4.20 . Moderate and high exposure were recategorized by 
varying the MG cutoff value by adding a second decimal point (first three models). Interestingly enough, the odds ratios increased from 1.83 to 3.30 (moderate exposure) and 3.98 to 5.41 (high exposure), when the cutoff value for MG was increased from 1.99 to 2.00. This phenomenon demonstrates how, in some data sets, marginal variations in the categorization of exposure can account for sizable differences in risk estimation. In the Baton Rouge data set, this finding could possibly be attributed to the use of a six-point ordinal scale. Use of a scale with more points would probably reduce the variation in the risk estimate. A careful assessment of the distribution of exposure across all individuals in the study (cases and referents) is necessary before adequate categorizations of exposure can be selected. Graphic methods, such as quantile-quantile (Q-Q) plots, can assist investigators in the choice of cutpoints for categorizing exposure (20).

In the first part of the southern Ontario study (table 5) all of the subjects were grouped with the use of an identical percentile point for all five exposure measures. The results were not markedly different, however, since the unexposed cases and referents were identical over all measures. Reclassification was observed only between the moderate and high groups. To approximate and compare this data set with that of the Baton Rouge study, we categorized subjects in the southern Ontario study in a similar manner (table 6), by defining the lowest exposure category as no-or-low exposure (instead of exclusively unexposed as in part 1). The distribution of the total number of subjects according to degree of exposure was identical for CEI, MG, TWA grade, and TTE. Again, HG, being a discrete variable, could not be categorized in this model at the same percentile points, so a slightly different distribution was observed. All of the variables rendered comparable odds ratios for moderate exposure. For high exposure, interestingly enough, CEI, TWA grade, and TTE gave similar results (odds ratios of 5.44, 5.96, and 5.56, respectively), whereas the estimation of risk by MG was lower, 3.06. It is noteworthy that MG, which gave the higher risk estimate in the Baton Rouge study, produced the lowest odds ratio in this study. In this particular case, since this phenomenon was not observed in the first part of the analysis, we speculate that the obtained results may be a consequence of misclassification. The difference between MG and the other summary measures was observed only for the high-exposure category. Since this category contained only $12.8 \%$ of the subjects, a small degree of misclassification could markedly affect the results, particularly since we used a matched design and analysis (21). An alternative explanation would be that MG may be more stable and less sensitive to extremes.

Assignment of cases and referents to a particular category of exposure varies according to the summary measure being used (1). This redistribution could be interpreted as misclassification, and the results obtained could be considered biased. We would, there- fore, be assuming that one or more of the exposure measures are "correct," and the others inadequate. If misclassification occurred at random, then the summary exposure measure that results in the greatest odds ratio is the one least subject to this type of bias - since random misclassification attenuates risk estimation towards the null (22). However, if it is nonrandom, the resultant bias could effect a shift of the odds ratio in either direction. This bias has been shown to be increased in matched studies when they are compared with unmatched ones (21). Empirical calculations of risk, assuming reasonable estimates of the extent of misclassification, have been proposed for analyses of the effects of potential misclassification bias $(23,24)$.

Another way of interpreting the differences observed is by examining the relationship that each particular summary measure may have with a potentially causal effect. Differences observed when using several measures may suggest a particular causal mechanism. For example, a high risk given by TTE, combined with a lower risk given by CEI, may indicate that the length of exposure is more relevant than the intensity of exposure. To the contrary, a high odds ratio with CEI or HG (which are independent of time) with lower risk with TTE suggests that intensity is more relevant than duration of exposure. A recent case-referent study reported the association of respiratory cancer to arsenic exposure using several measures of exposure (25). Measures of exposure related to intensity were good predictors of respiratory cancer mortality, whereas duration of employment was not a significant risk variable. This finding suggests that intensity of exposure to arsenic is more relevant than duration in the development of respiratory cancer.

The Baton Rouge data showed increased risk estimates for high levels of exposure to sulfuric acid when MG and HG were used to define exposure. Let us suppose that the similarity between the cases and referents in terms of duration of employment was not artificially created by matching. In this situation, the obtained results (high risks when using measures independent of time and lower risks with the time-dependent measures) would suggest that the intensity of exposure to sulfuric acid was more relevant than the length of exposure in the development of laryngeal cancer. Yet this conclusion cannot ve supported by the Baton Rouge study since its cases and referents were matched on duration of employment.

The purpose of the present analysis was not to demonstrate an association between sulfuric acid exposure and laryngeal cancer, but to examine empirically the effects of using different summary exposure measures in the estimation of risk. It has been shown that two different case-referent studies on the same agent-disease association gave different results across the various measures used. This phenomenon can be attributed, at least in part, to methodological differences. 
Often, there is no prior knowledge of the physiological effects of the association under study. Hence it is difficult to select an exposure measure that will accurately reflect the causal and temporal relationship. It is clear that, with a range of summary worklife exposure measures to select from, it is possible to draw different and even contradictory conclusions using the same data set. If differences among the various measures are found, causal (biological) and noncausal (methodological) explanations should be sought. To complement results based on analyses using worklife summary exposure measures, trends across variously lagged induction time windows can also assist in explaining exposure and disease relationships.

We recommend that, in the absence of a definitive model for assessing exposure, a variety of measures be used to determine risk. This approach would also facilitate the comparison of findings across studies.

\section{Acknowledgments}

This work was based on papers presented under similar titles at the following meetings: The Second International Symposium on Epidemiology in Occupational Health, Montreal, 23-25 August 1982; Research Day, University of Toronto, Division of Community Health, 12 April 1983; The Society for Epidemiologic Research, Amherst, 17-19 June, 1987. The feedback from colleagues at these meetings has been both stimulating and valuable in the preparation of this manuscript.

Professor JD Burch, Dr GR Howe, and Dr AB Miller were responsible for gathering the data for the southern Ontario study. Dr J Siemiatycki, Dr R Lakhani, and Mr R Dewar were responsible for estimating and grading exposure in the southern Ontario data set.

This paper is dedicated to the memory of Fred Venable, the industrial hygienist, without whom the Baton Rouge study could not have been successfully completed.

\section{References}

1. Walker AM, Blettner M. Comparing imperfect measures of exposure. Am J Epidemiol 1985;121:783-90.

2. Smith TJ. Exposure assessment for occupational epidemiology. Am J Ind Med 1987;12:249-68.

3. Soskolne CL. Upper respiratory cancer among refinery and chemical plant workers: a case-control study in Baton Rouge, Louisiana [dissertation]. University Microfilms Int 1982;43(03):327p.

4. Soskolne CL, Zeighami EA, Hanis NM, Kupper LL, Herrmann N, Amsel J, et al. Laryngeal cancer and occupational exposure to sulfuric acid. Am J Epidemiol $1984 ; 120: 358-69$.

5. Burch JD, Howe GR, Miller AB, Semenciw R. Tobacco, alcohol, asbestos and nickel in the etiology of cancer of the larynx: a case-control study. J Natl Cancer Inst 1981;6:1219-24.

6. Lynch J, Hanis NM, Bird MG, Murray KJ, Walsh JP. An association of upper respiratory cancer with exposure to diethyl sulfate. J Occup Med 1979;21:333-41.

7. Gamble J, Spirtas R. Job classification and utilization of complete work histories in occupational epidemiology. J Occup Med 1976;18:399-404.

8. Soskolne CL, Jhangri GS, Siemiaticki J, Lakhani R, Dewar R, Burch JD, et al. Occupational exposure to sulfuric acid associated with laryngeal cancer, southern Ontario, Canada. Scand J Work Environ Health 1992;18: 225-32.

9. Gérin M, Siemiatycki J, Kemper H, Bégin D. Obtaining occupational exposure histories in epidemiologic casecontrol studies. J Occup Med 1985;27:420-26.

10. Siemiatycki J, Richardson L, Gérin M, Goldberg M, Dewar R, Désy M, et al. Associations between several sites of cancer and nine organic dusts: results from an hypothesis-generating case-control study in Montreal 1979-1983. Am J Epidemiol 1986;123:235-49.

11. Siemiatycki J, Wacholder S, Richardson L, Dewar R, Gérin M. Discovering carcinogens in the occupational environment: methods of data collection and analysis of a large case-referent monitoring system. Scand J Work Environ Health 1987;13:486-92.

12. Siemiatycki J. Dewar R, Nodon L, Gérin M, Richardson $\mathrm{L}$, Wacholder $\mathrm{S}$. Associations between several sites of cancer and twelve petroleum-derived liquids: results from a case-referent study in Montreal. Scand J Work Environ Health 1987;13:493-504.

13. Breslow NE, Day NE. Statistical methods in cancer research; vol 1 (The analysis of case-control studies). Lyon: International Agency for Research on Cancer, 1980: 247-79.

14. Statistics and Epidemiology Research Corporation. EGRET $^{\circledR}$. Seattle, WA: Statistics and Epidemiology Research Corporation, Software Division, 1988.

15. Ahlborg G Jr, Hogstedt C, Sundell L, Aman CG. Laryngeal cancer and pickling house vapors [letter]. Scand $\mathbf{J}$ Work Environ Health 1981;7:239-40.

16. Cookfair DL, Wende KE, Michalek AM, Vena J. A case-control study of laryngeal cancer among workers exposed to sulfuric acid [abstract]. Am J Epidemiol 1985;122:521.

17. Beaumont JJ, Leveton J, Knox K, Bloom T, McQuiston $\mathrm{T}$, Young $\mathbf{M}$, et al. Lung cancer mortality in workers exposed to sulfuric acid mist and other acid mists. J Natl Cancer Inst 1987;79:911-21.

18. Steenland K, Schnorr T, Beaumont J, Halperin W, Bloom T. Incidence of laryngeal cancer and exposure to acid mists. $\mathrm{Br} \mathrm{J}$ Ind Med 1988;45:766-76.

19. Soskolne CL, Pagano G, Cipollaro M, Beaumont J, Giordano G. Epidemiologic and toxicologic evidence for chronic health effects and the underlying biologic mechanisms involved in sub-lethal exposure to acidic pollutants. Arch Environ Health 1989;44:180-91.

20. Wartenberg D, Northridge M. Defining exposure in casecontrol studies: a new approach. Am J Epidemiol 1991; 133:1058-71.

21. Greenland $S$. The effect of misclassification in matchedpair case-control studies. Am J Epidemiol 1982;116: 402-6.

22. Rothman KJ. Modern epidemiology. Boston/Toronto: Little, Brown and Co, 1986.

23. Reade-Christopher SJ, Kupper LL. Effects of exposure misclassification on regression analysis of epidemiologic follow-up study data. Biometrics 1991;47:535-48.

24. Weinkam JJ, Rosenbaum WL, Sterling TD. A practical approach to estimating the true effect of exposure despite imprecise exposure classification. Am J Ind Med 1991;19:587-601.

25. Lee-Feldstein A. A comparison of several measures of exposure to arsenic: matched case-control study of copper smelter employees. Am J Epidemiol 1989;129:11224.

Received for publication: 21 November 1991 